\title{
Non-Newtonian material behaviour in extrusion-based 3D printing: Investigation of critical process parameters
}

\author{
M. Brillinger', K. A. Pendl ${ }^{2}$ \\ ${ }^{1}$ Area 4.2: Cognitive Production Systems, Pro2Future GmbH, Graz, Austria \\ markus.brillinger@pro2future.at \\ ${ }^{2}$ Institute of Strength of Materials, University of Technology, Graz, Austria \\ kevin.pendl@student.tugraz.at
}

\begin{abstract}
During the last years, the development of processes for 3D-printing has been driven forward. Besides optimizing the printing process and developing new types of processes by altering components of the printer for example, research is also being pursued to investigate new materials suitable for 3D printing, including extrusion-based processes. Most of the printing materials show non-Newtonian behaviour within certain limits. Understanding the rheology of these materials but also the impact on the whole printing process can be a key factor for the printing quality. The origin of this paper is the attempt to point out critical process parameters in the process development of extrusion-based processes using materials with non-Newtonian behaviour. Focus is set on four types of materials including polymers, slurries, foods and biomaterials. After a short summary of the state of the art, the critical process parameters are discussed. The present paper shows that parameters like a shear-thinning or thixotropic behaviour, the sort of the filler material as well as the temperature and yield stress are of great importance for all four discussed groups.
\end{abstract}

Keywords: 3D printing, non-Newtonian, Material behaviour, Process parameters

\section{Introduction}

A common problem when using an extrusion-based system is the clogging of the nozzle due to not ideally adjusted printing parameters [1]-[4]. Another issue is the overfilling of material at locations where there is a change of the printing direction [5]. This can reduce the printing quality in these areas and affects the mechanical properties of the printed parts. These problems can be linked to the rheology of the used material. Understanding the flow behaviour of the liquified material helps to cope with the challenges of the printing process. All rheological mechanisms occur between two extremes: ideal viscous flow (liquids) and ideal elastic deforming (solids) [6]. Therefore, all real substances have both viscous and elastic behaviour. When the viscosity depends on the shear rate, this behaviour is called non-Newtonian [6] [7]. Fig. 1 shows the general types of non-Newtonian fluids.
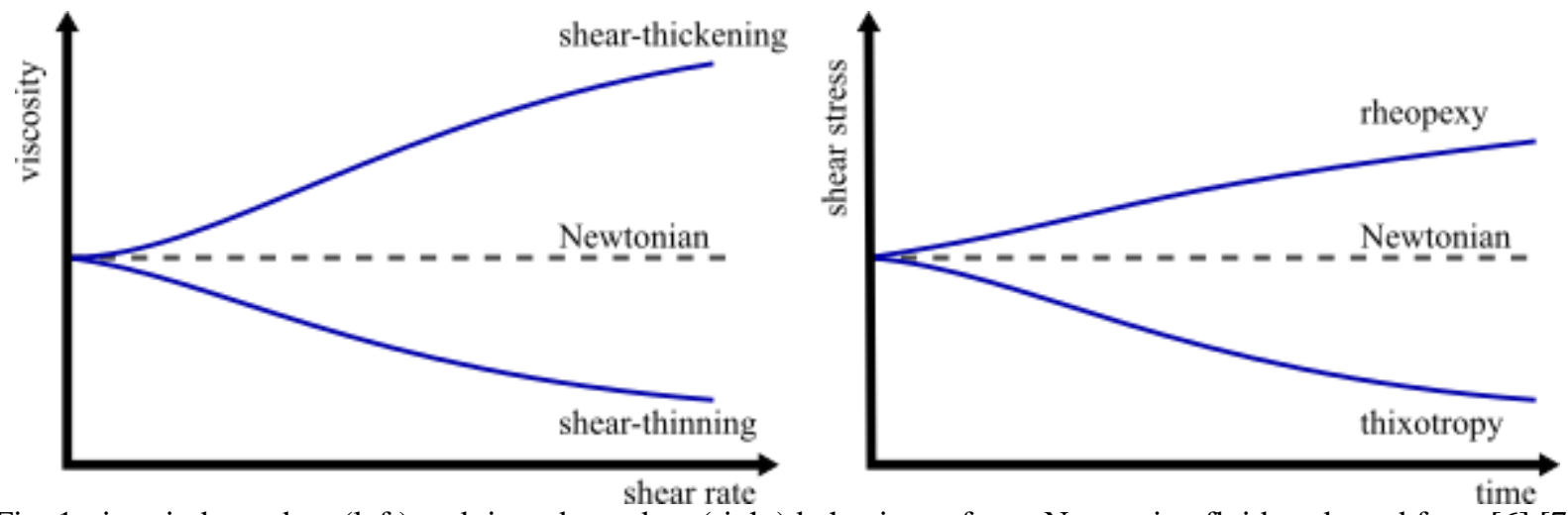

Fig. 1: time-independent (left) and time-dependent (right) behaviour of non-Newtonian fluids, adapted from [6] [7]

In terms of time-independent behaviour, one has to distinguish between "shear-thinning" and "shear-thickening". Shear-thinning fluids, also called pseudoplastic, exhibit a decreasing viscosity with increasing shear rate. In contrast, if a fluid is called shear-thickening or dilatant, the viscosity increases with increasing shear rate. In the case of timeindependent behaviour one can distinguish between thixotropic and rheopectic fluids. The longer the duration of an applied stress is, the more the apparent shear stress will decrease or increase, respectively [7]. 
Despite it is challenging to describe the rheological behaviour accurately, exploiting the characteristics of nonNewtonian materials can be advantageous for the printing process. Hence, this paper attempts to give an insight into the state of the art of materials used in extrusion-based processes with non-Newtonian behaviour. In addition, critical parameters addressing this issue are investigated.

In this paper, focus is set on four types of 3D printing materials with non-Newtonian behaviour:

- Polymers, that form the first category but also appear as additives in other groups

- Slurries, that are defined as a pasty mixture of water and small pieces of a solid in a specific ratio [8]

- Foods, for which giving meals an aesthetic look by extruding the ingredients can be pioneering in modern cuisine

- Biomaterials and their use in tissue engineering or consideration of environmentally friendly materials

The present paper is structured as follows: The next section summarizes the outcome of the literature study regarding the use of materials with non-Newtonian behaviour. Besides an overview of the state of the art in tabular form, section 2 presents the basic idea of selected references of Table 1. In section 0 critical parameters that influence the printing behaviour of the materials mentioned in section 2 are discussed. While in the first subsection the critical parameters are agglomerated to specific thematic fields, the second subsection exhibits intersecting parameters for the investigated materials. The third subsection discusses considerable parameters for new materials in extrusion-based processes. In the last section the outcome of the paper is summarized.

\section{State of the art}

In this section a summary of the state of the art regarding extrusion-based processes with non-Newtonian material behaviour is presented. Table 1 shows the outcome of the initial literature study. In it the rheological properties of certain materials, utilized extrusion-based processes and submitted patents are summarized. The rheology of the materials is differentiated into pseudoplastic (P), dilatant (D), thixotropic $(T)$ and rheopectic $(R)$ behaviour. A " $x$ " after a source indicates that a patent has not yet been granted.

Table 1: Overview of non-Newtonian material behaviour in extrusion-based 3D-printing

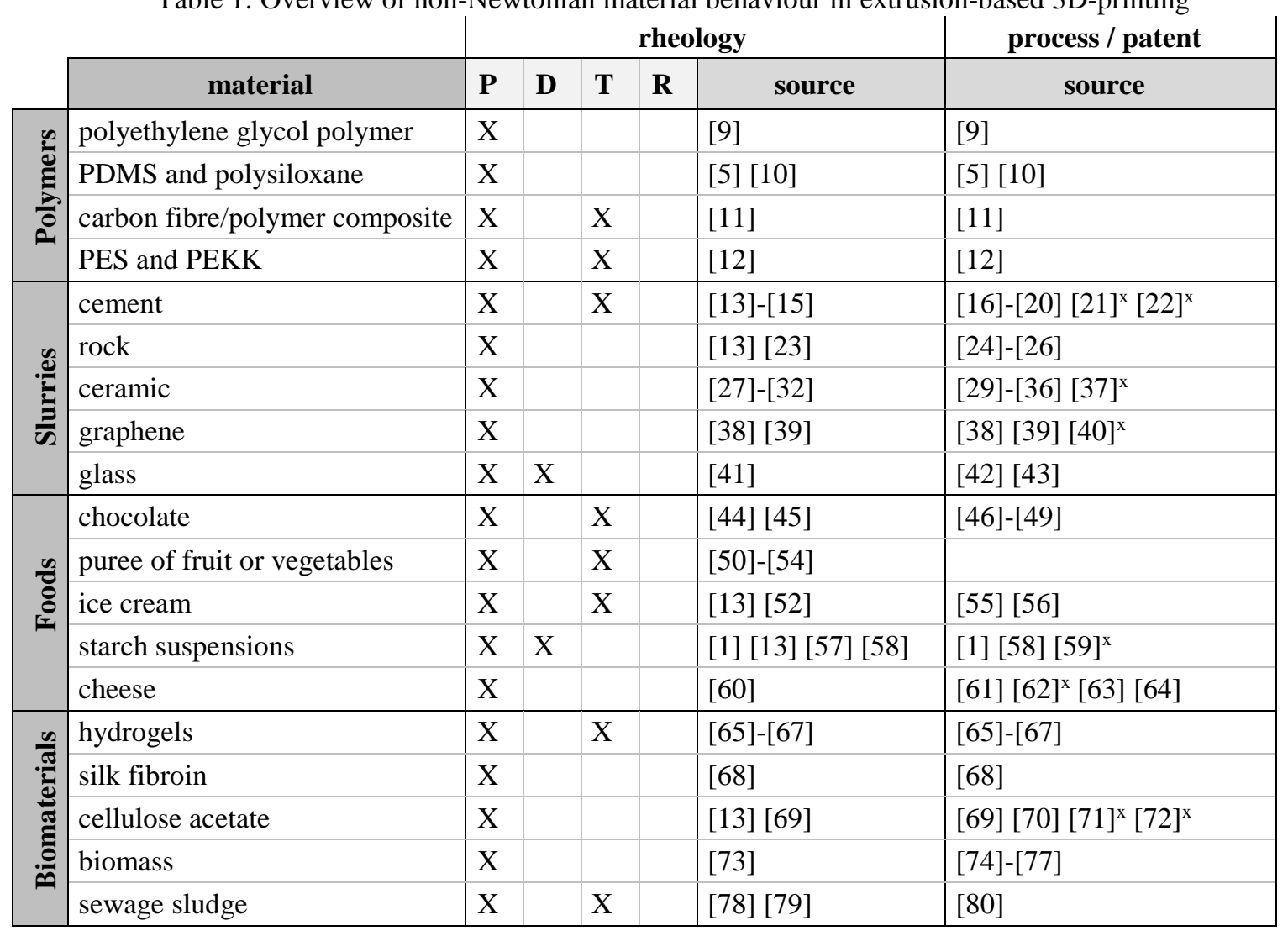




\subsection{Polymers}

The use of polymers in 3D printing and their rheology is well determined [13] [81]-[83]. Bengtsson [9] investigated the printing behaviour of PEG2000, mixed with a carbonate-based plasticizer. It exhibits shear-thinning behaviour, has mechanical and chemical stability and can be used as sacrificial template material in microsystems and for biological applications. Ozbolat et al. [10] found a new way of processing polydimethylsiloxane (PDMS), a silicone used in medical industry. While moulding or casting PDMS limits the geometrical complexity of the manufactured parts, admixing the two elastomers Sylgard 184 and SE 1700 in a specific ratio leads to an extrudable material which exhibits shear-thinning behaviour with a high mechanical strength. Liravi et al. [5] implemented a finite element analysis for nozzle dispensing of polysiloxane. The results of the simulation can be used to predict optimal working parameters like extrusion pressure and distance from the substrate.

\subsection{Slurries}

Their use in 3D printing mainly focuses on applications in architecture or art. While the influence of yield stress on the printability of cement-based materials was investigated by Perrot et al. [17], Hambach and Volkmer [18] examined the alignment of fibers in cement slurries and their impact on physical properties. Wang et al. [16] discussed the printability of cement slurries with added copper tailings in order to recycle waste. Besides using ceramic slurries for pottery, there are also bioinspired applications: On the one hand, Feilden et al. [29] [30] researched ceramic composites mixed with a hydrogel, imitating textured microstructures of bones and shells. On the other hand, Compton and Lewis [33] created structures made of inter alia ceramics inspired by balsa wood using an epoxy-based ink. Extrusion-based glass 3D printers can be based on two main principles: On the one hand there is a process for molten glass developed by Klein et al. [42], on the other hand printing glass at room temperature with a sintering process afterwards was implemented by Nguyen et al. [43]. In addition to this and therefore not mentioned in Table 1, supersaturated salt solutions which are a mixture of solid undissolved salt particles and a liquid, e.g. water, can also be added to the group of slurries in the broader sense. Brillinger et al. [84] investigated the printability of sodium acetate trihydrate which can be classified as a supersaturated salt solution.

\subsection{Foods}

As it is part of modern cuisine, when 3D printing foods, they are primarily used for "uncommon or odd ways of food arrangement". Hence, the goal of "manufacturing" foods in 3D printing is not building 3D objects with specific mechanical or physical properties. The research revealed that non-Newtonian properties are not being exploited in food printing yet. Although there is enough rheological research, the implementation focuses primarily on the printability of different types of foods. Most of the materials shown in the table above can be printed with so called food printers. The launched printers are mainly based on the one's of the big players (Prusa, MakerBot, Ultimaker) but research for new food printers and processes is not really driven forward [85]. While most of extrusion-based 3D printers liquefy the material by heating, there is even a food printer for ice cream, created at MIT [55]. Others printed ice cream as well, like the Spanish work group "Robots in Gastronomy" [56]. Apart from that, Liu et al. [58] investigated the rheology as well as printing quality of mashed potatoes mixed with potato starch. Lille et al. [1] researched the printability of different fibre-rich materials like starch, milk powder or oat. They determined a connection between the printing stability and yield stress and obtained the best printing precision with a semi-skimmed milk powered-based paste.

\subsection{Biomaterials}

Li et al. [65] studied the rheological properties and the printability of hydrogels based on alginate. The results showed that alginate hydrogels are not ideal materials for extrusion-based printing due to the low viscosity recovery. A proposed solution of this issue is to add up a small amount of graphene oxide. Zhang et al. [66] researched the use of dual-responsive hydrogels with extrusion techniques for tissue engineering. The prospective use of silk fibroin scaffolds in tissue engineering due to the biocompatibility was examined by Ghosh et al. [68]. Pattinson and Hart [70] developed a 3D printer for cellulose acetate. By dissolving cellulose in acetone, it can be printed through a nozzle. In addition to this, Wang et al. [69] did a sophisticated survey of cellulose materials used in 3D printing. It is not only limited to extrusion-based processes and also includes the examination of the rheology. Kucherov et al. [74] used polyethylene-2,5-furandicarboxylate (PEF) for an extrusion-based process. The material has better chemical resistance than other polymers and it can be considered as an economic and environmentally friendly material. 


\section{Discussion}

\subsection{Critical parameters influencing extrusion-based processes}

In this section, the outcome of the aggregation of critical parameters influencing non-Newtonian material behaviour is presented. Screening the state of the art presented in chapter 2, all mentioned parameters were categorized, and an attempt was made to arrange them graphically in a clear way. Although the research was conducted by different research institutions by academics and scientists around the world, a common approach has been identified on how to implement the use of a certain non-Newtonian material for extrusion processes:

1) Preparation of an applicable blend (ratio of matrix material, filler material(s), disperser(s) and other additives)

2) Rheological survey of the requested material in accordance to the mixed blend

a) Investigation of the viscosity as a function of the shear rate and finding the range of shear-thinning behaviour.

b) If competences and infrastructure are available: Compiling the corresponding theoretical model (power-law, Herschel-Bulkley, ...) and comparing it to the experimental data.

3) Derivation of appropriate extrusion parameters in accordance to the rheology of the material.

4) Variation of the extrusion parameters for the requested flowability/ extrudability/ buildability.

a) If accessible: Comparing the results with simulations/FE-analysis.

b) Analysing the results for improvements and further work.

Following figure summarizes the critical parameters that have to be considered when printing materials with nonNewtonian behaviour in extrusion-based processes. The position of each parameter is an indicator of the influence of the respective thematic field. Parameters positioned on the corner of the triangle can be allocated to a single thematic field. If they are located along an edge of the triangle, the parameter affects the fields on the corners of this edge. Parameters inside the triangle are influenced by the printing process as well as the rheology and the material.

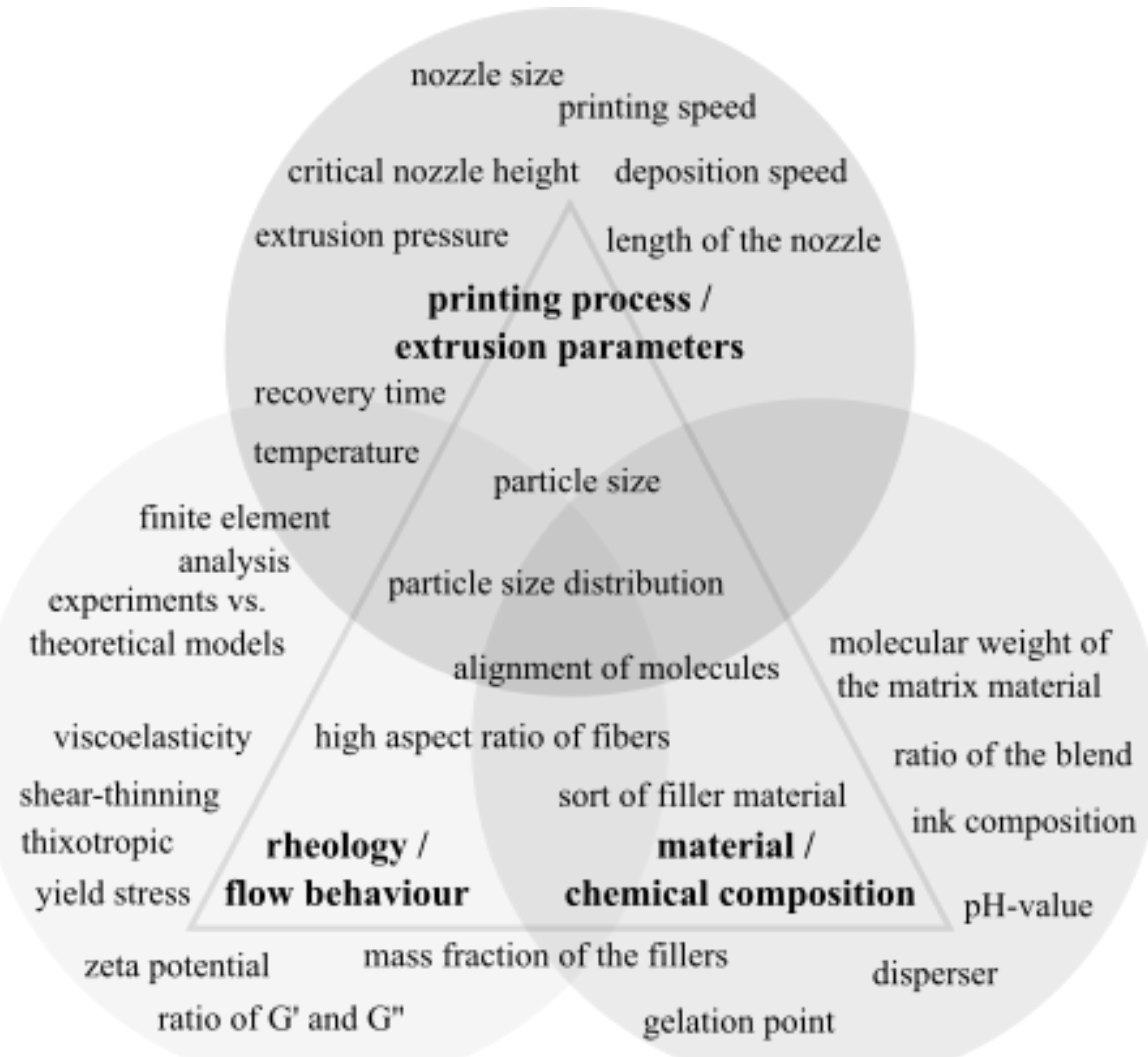

Fig. 2: Critical parameters influencing non-Newtonian material behaviour. 
The most important circumstance when printing with an extrusion-based system is the appropriate reconcilement of all influencing parameters. If this is not correctly done, the printing of the material will not be executed properly.

Reconsidering the list above, after picking the material that is to be printed, there are diverse options to alter its properties. First of all, the mixture of the blend is necessary for printing the material [10]. This is equivalent to an ideal ink composition [38] which is affected by all types of fillers [12] [32] [35] [58] [65], fibers [11] [18], dispersers [31] and other additives. Another aspect is the molecular weight [35] [70] of the matrix material.

The second point of the mentioned approach is a rheometric investigation of the material's rheology. Additionally, it has to be considered that the rheology of the liquified material has an effect on clogging the nozzle. This is why all studies aim a shear-thinning or/and thixotropic behaviour of the material. But also a viscoelastic [33] [67] behaviour can be beneficial for the printing process. Solving the problem of clogging the nozzle, Heymann [86] investigated the influence of ultrasound devices on non-Newtonian behaviour of polymers. By exciting the edge area of the nozzle, the viscosity of the deposited material (with shear-thinning properties) decreases. Other patents describe similar systems, they only differ in ambient devices [87] or in the excitation of the material [88]. The rheology is affected by the proposition of the material and especially by the mass fractions of the fillers/fibers [1] [11] [12] [18] [32] [35] [58] as well as the so-called gelation point [29] [38] [65] [66] in the case of hydrogels. The influence of the mass ratio of the fillers is represented by the Krieger-Dougherty-equation [2] [29] [31] [32] [67]. Another decisive parameter is the ratio of the loss and storage modulus (G' and G'") [1] [10] [38] [39] [58] [66] [68]. Wang and Shaw [34] claim that also the zeta potential, which is the electrokinetic potential at the shear layer of a particle in motion, as a function of the $\mathrm{pH}-$ value has a specific influence in the case of cement slurries.

The third and fourth point involve the extrusion of the material. A successful outcome of the process is intertwined with the right extrusion parameters. Common issues are the nozzle size (diameter) [11] [34], extrusion pressure [10] [5], deposition speed [68] as well as the printing speed [10]. In addition, the critical nozzle height is emphasized by Wang and Shaw [34]. Parameters that affect both the rheology as well as the printing process are the recovery time [65], temperature [12] [31] [58] [66] [78] and the comparison of theoretical models and experimental trials [5] [12] [29] [30] [34] [58] [67].

At last, there are parameters that influence all three mentioned thematic fields like the particle size [23] [34] and particle size distribution [29] [78], a high aspect ratio of the filler material [11] as well as the sort of the filler [32]. The alignment of the fibers [11] [18] [30] [68] is also mentioned and the effects are clearly derivable: The mass fraction of the fibers coheres with the blend of the extrusion material. It influences the alignment of the fillers and therefore the rheology. The alignment itself is a function of the velocity gradient which is controlled by the nozzle length. In general, the coordination of all three parameters is essential to influence the alignment of fibers.

\subsection{Intersecting parameters for different materials}

It was mentioned that there are several intersections between the publications that were investigated. Therefore, Fig. 3 shows this relation graphically. It can be seen that most of the determined parameters were found in published work including polymers and slurries as well as that there are not so much for foods. The explanation for this is that most publications and patents regarding 3D-printing of foods focus on the printing of the food itself and not really on characteristics during printing or mechanical properties afterwards. In general, mechanical properties are not a crucial issue in cuisine.

Fig. 3 shows the intersection of the critical parameters influencing non-Newtonian material behaviour in 3Dprinting in terms of their reference in the reviewed papers. If the same parameter or a similar one is mentioned for different materials, they are positioned in the respective intersecting field. Critical parameters in the middle of the Venn-diagram were mentioned in publications of all four material types. These include especially rheological properties, like a shear-thinning behaviour or the ratio of G' and G', but also the sort of the filler material as well at the temperature while printing is crucial. In contrast to this, there are certain aspects seemingly only influencing specific types of materials. This is due to the fact that these factors have no influence for another material or have not yet been considered. 


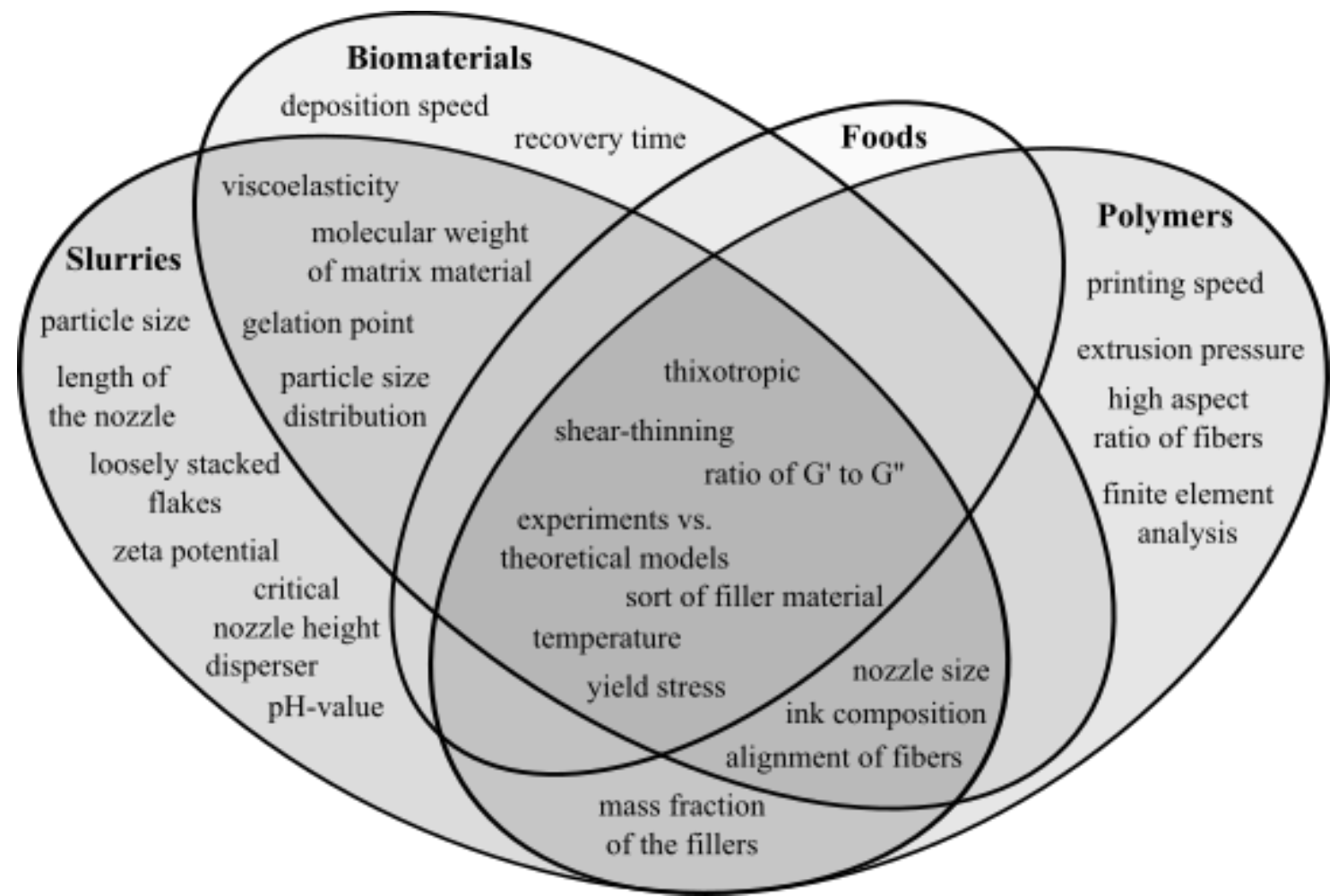

Fig. 3: Venn diagram - intersecting parameters of non-Newtonian material behaviour in 3D-printing.

\subsection{Developing extrusion-based processes for new materials}

Considering the paragraphs above, the present paper lead to following statements for investigating new materials for extrusion-based processes: First of all, material research is very important. It is necessary knowing properties in solid and liquid state as well as the influence of additives. Furthermore, understanding the rheology is necessary. For a good printing result, the material should not clog the nozzle, shear-thinning behaviour prevents it for example. In addition, the behaviour after printing is important as well. Considering the time until printing the next layer, a thixotropic behaviour provides information about that matter. Lastly, the process execution is not trivial and mostly "best practice". Even if someone understands the material and its rheology thoroughly, there can be some aspects that cannot be predicted beforehand. The extrusion process and its parameters are still adjusted according to experience, so besides knowing about the material and rheology, knowledge about the printing process is of essential importance.

\section{Conclusion}

The present paper exhibits a graphical representation of intertwining parameters which should be considered in newly developed 3D-printing processes. Especially, when dealing with new materials with non-Newtonian behaviour knowledge about parameters like the yield stress, the sort and ratio of the filler material as well as the range of thixotropic behaviour can be key factor in the development of the printing process. Furthermore, the comparison between theoretical models and simulation with experiments should not be neglected.

This paper has set the focus on four different types of material with non-Newtonian material behaviour and shows a wide range of parameters that are already state of the art in extruding materials. An attempt to aggregate the parameters to superordinate thematic fields was made and can be seen in Fig. 2. In this matter it should be added that the present paper cannot be seen as guideline on how to proceed when investigating a new material.

Considering the proposed "triarchy" of material, rheology and printing process, the present paper points out the required interdisciplinarity and all the essential competences for investigating and printing new materials with nonNewtonian behaviour. It is a big success factor for developing the process knowing about possible influences and one should not anticipate important parameters if the necessary knowledge is missing. 


\section{References}

[1] M. Lille, A. Nurmela, E. Nordlund, S. Metsä-Kortelainen and N. Sozer, "Applicability of protein and fiber-rich food materials in extrusion-based 3D printing," Journal of Food Engineering, 2018.

[2] J. A. Lewis, J. E. Smay, J. Stuecker and J. Cesarano, "Direct ink writing of three-dimensional ceramic structures," Journal of the American Ceramic Society, 2006.

[3] J. Flynt, “3DInsider," 0108 2019. [Online]. Available: https://3dinsider.com/3d-printer-nozzle-clogging/. [Accessed 2501 2020].

[4] Y. Tlegenov, W. F. Lu and G. S. Hong, "A dynamic model for current-based nozzle condition monitoring in fused deposition modelling," Progress in Additive Manufacturing, Vol. 4, pp. 221-223, 2 July 2019.

[5] F. Liravi, R. Darleux and E. Toyserkani, "Additive manufacturing of 3D structures with non-Newtonian highly viscous fluids: Finite element modeling and experimental validation," Additive Manufacturing, 2017.

[6] T. G. Mezger, Das Rheologie Handbuch, 5th edition, Hannover: Vincentz Network GmbH \& Co. KG, 2016.

[7] F. Irgens, Rheology and Non-Newtonian Fluids, Trondheim: Springer International Publishing Switzerland, 2014.

[8] C. A. L. Dictionary, "“slurry"," in Cambridge Advanced Learner's Dictionary, 3rd ed., Cambridge, UK, Cambridge University Press, 2008, p. 1358.

[9] K. Bengtsson, "Additive manufacturing methods and materials for electrokinetic systems," Lingköping, 2015.

[10] V. Ozbolat, M. Dey, B. Ayan, A. Povilianskas, M. C. Demirel and I. T. Ozbolat, "3D Printing of PDMS Improves Its Mechanical and Cell Adhesion Properties," ACS Biomaterials Science and Engineering, 2018.

[11] J. P. Lewicki, J. N. Rodriguez, C. Zhu, M. A. Worsley, A. S. Wu, Y. Kanarska, J. D. Horn, E. B. Duoss, J. M. Ortega, W. Elmer, R. Hensleigh, R. A. Fellini and M. J. King, "3D-Printing of Meso-structurally Ordered Carbon Fiber/Polymer Composites with Unprecedented Orthotropic Physical Properties," Scientific Reports, 2017.

[12] V. Kishore, X. Chen, C. Ajinjeru, A. A. Hassen, J. Lindahl, J. Failla, V. Kunc and C. Duty, "ADDITIVE MANUFACTURING OF HIGH PERFORMANCE SEMICRYSTALLINE THERMOPLASTICS AND THEIR COMPOSITES," 2016.

[13] N. P. Cheremisinoff, Polymer Mixing and Extrusion Technology, New York: Marcel Dekker Inc., 1987.

[14] B. H. Min, L. Erwin and H. M. Jennings, "Rheological behaviour of fresh cement paste as measured by squeeze flow," Journal of Material Science, Vol. 29 No. 5, pp. 1374-1381, 1993.

[15] H. Hodne, "Rheological performance of cementious materials used in well cementing," Stavanger, 2007.

[16] G. Ma, Z. Li and L. Wang, "Printable properties of cementitious material containing copper tailings for extrusion based 3D printing," Construction and Building Materials, 2018.

[17] A. Perrot, D. Rangeard and A. Pierre, "Structural built-up of cement-based materials used for 3D-printing extrusion techniques," Materials and Structures/Materiaux et Constructions, 2016.

[18] M. Hambach and D. Volkmer, "Properties of 3D-printed fiber-reinforced Portland cement paste," Cement and Concrete Composites, 2017.

[19] Y. Qianrong and L. Qiaoling, "3D printing cement-based material and preparation method thereof”. China Patent CN104891891B, 2017.

[20] X. Xiqiang, L. Jingfang, Z. Tao, H. Liang, Z. Nan, L. Juan and L. Guoyou, "Cement-based composite material used for 3D printing technology as well as preparation method and application thereof". China Patent CN104310918B, 2016.

[21] M. Guowei and W. Li, “Array type 3D printer for cement-based material”. China Patent CN201710965576, 2017.

[22] X. Jiru and Z. Dunpu, "Dry-mixed mortar material for 3D printing and preparation and application thereof". China Patent CN201610347021, 2016.

[23] P. K. Senapati, D. Panda and A. Parida, "Predicting Viscosity of Limestone-Water Slurry," Journal of Minerals \& Materials Characterization \& Engineering, Vol. 8 No. 3, 2009.

[24] “Desamanera Homepage,” Desamanera S.r.l., [Online]. Available: http://www.desamanera.com/en. [Accessed 25 
$012020]$.

[25] "Marble EcoDesign Homepage," 3D Marble Eco Design, [Online]. Available: http://www.marbleecodesign.com/. [Accessed 2501 2020].

[26] H. Liang and T. Danna, "Material design 3D printing process based on rock and soil models". China Patent CN201611117932, 2016.

[27] J. Kolczyk and J. Zych, "Rheological Properties Of Ceramic Slurries With Colloidal Binders Used In The Investment Casting Technology," Metalurgija, Vol. 52 No. 1, pp. 55-58, 2012.

[28] J. Kolczyk, Ł. Jamrozowicz and N. Kaźnica, "Rheological Properties of Typical Ceramic Slurries Used in the Lost Wax Technology,” Archives of Foundry Engineering, Vol. 17 No. 1, pp. 197-201, 2017.

[29] E. Feilden, E. G. T. Blanca, F. Giuliani, E. Saiz and L. Vandeperre, "Robocasting of structural ceramic parts with hydrogel inks," Journal of the European Ceramic Society, 2016.

[30] E. Feilden, E. D’Elia, L. Vandeperre, F. Giuliani, C. Ferraro, Q. Zhang, E. Saiz and E. García-Tuñón, “3D Printing Bioinspired Ceramic Composites," Scientific Reports, 2017.

[31] S. C. Danforth, G. Qi, N. Venkataraman, A. Safari and S. Rangarajan, "Powder Processing, Rheology, and Mechanical Properties of Feedstock for Fused Deposition of Si3N4 Ceramics," Journal of the American Ceramic Society, 2000.

[32] M. Faes, H. Valkenaers, F. Vogeler, J. Vleugels and E. Ferraris, "Extrusion-based 3D printing of ceramic components," in Procedia CIRP, 2015.

[33] B. G. Compton and J. A. Lewis, "3D-printing of lightweight cellular composites,” Advanced Materials, 2014.

[34] J. Wang and L. L. Shaw, "Rheological and extrusion behavior of dental porcelain slurries for rapid prototyping applications," Materials Science and Engineering A, 2005.

[35] W. J. Costakis, L. M. Rueschhoff, A. I. Diaz-Cano, J. P. Youngblood and R. W. Trice, "Additive manufacturing of boron carbide via continuous filament direct ink writing of aqueous ceramic suspensions," Journal of the European Ceramic Society, 2016.

[36] S. Guoping, L. Miaomiao and X. Fangmin, "Method for 3D ceramic printing forming". China Patent CN104526838B, 2017.

[37] C. S. Nordahl, "Ceramics with engineered microstructures via $3 \mathrm{~d}$ printing and templated grain growth". USA Patent US14725203, 2015.

[38] L. Dong, Z. Chen, X. Zhao, J. Ma, S. Lin, M. Li, Y. Bao, L. Chu, K. Leng, H. Lu and K. P. Loh, "A nondispersion strategy for large-scale production of ultra-high concentration graphene slurries in water," Nature Communications, 2018.

[39] C. Zhu, T. Y. J. Han, E. B. Duoss, A. M. Golobic, J. D. Kuntz, C. M. Spadaccini and M. A. Worsley, "Highly compressible 3D periodic graphene aerogel microlattices," Nature Communications, 2015.

[40] Y. Zhongzhen, Y. Jing, L. Xiaofeng, A. Fei and M. Peng, "Easily processed oxidized graphene slurry usable for 3D (three-dimensional) printing, preparation method of slurry and application of slurry". China Patent CN201710770763, 2017.

[41] D. T. N. Chen, Q. Wen, P. A. Janmey, J. C. Crocker and A. G. Yodh, "Rheology of Soft Materials," Annual Review of Condensed Matter Physics, Vol. 1, pp. 301-322, 2010.

[42] J. Klein, M. Stern, G. Franchin, M. Kayser, C. Inamura, S. Dave, J. C. Weaver, P. Houk, P. Colombo, M. Yang and N. Oxman, "Additive Manufacturing of Optically Transparent Glass," $3 D$ Printing and Additive Manufacturing, Vol. 2 No. 3, pp. 92-105, 2015.

[43] D. T. Nguyen, C. Meyers, T. D. Yee, N. A. Dudukovic, J. F. Destino, C. Zhu, E. B. Duoss, T. F. Baumann, T. Suratwala, J. E. Smay and R. Dylla-Spears, "3D-Printed Transparent Glass," Advanced Materials, Vol. 29 No. 26., 2017. 
[44] S. C. S. Lannes and E. V. Gonçalves, "Chocolate rheology," Ciência e Tecnologia de Alimentos, Vol. 30 No. 4, pp. 845-851, 2010.

[45] Đ. Ačkar, S. Škrabal, D. Šubarić, J. Babić, B. Miličević and A. Jozinović, "Rheological Properties of Milk Chocolates asInfluenced by Milk Powder Type, Emulsifier, andCocoa Butter Equivalent Additions," nternational Journal of FoodProperties, 18:7, pp. 1568-1574, 2015.

[46] D. A. Mantell, A. W. Hays and Z. C. Langford, "Printed chocolate structures". Spain Patent EP2937206B1, 2016.

[47] J. S. Batchelder, "Additive manufacturing system and method with interchangeable cartridges for printing customized chocolate confections". USA Patent US8986767B2, 2015.

[48] L. Hai, R. Fangping and S. S. Tao, "Chocolate for 3D printing and preparation method thereof". Patent CN104413230B, 2017.

[49] F. Li, P. Wenqi and L. Xuefang, "Triple-arm food 3D printing and rapid prototyping device". China Patent CN104207319B, 2016.

[50] C. Ditchfield, C. C. Tadini, R. Singh and R. T. Toledo, "Rheological Properties of Banana Puree at High Temperatures," International Journal of Food Properties, Vol. 7 No. 3, pp. 571-584, 2004.

[51] M. K. Krokida, Z. B. Maroulis and S. G. D., "Rheological Properties Of Fluid Fruit And Vegetable Puree Products: Compilation Of Literature Data," International Journal of Food Properties, Vol. 4 No. 2, pp. 179-20, 2001.

[52] G. Bylund, Dairy processing handbook, Lund, Sweden: Tetra Pak Processing Systems AB, 2003.

[53] X. Li, Y. Fang, H. Zhang, K. Nishinari, S. Al-Assaf and G. O. Phillips, "Rheological properties of gum arabic solution: From Newtonianism to thixotropy," Food Hydrocolloids, Vol. 25 No. 3, pp. 293-298, 2011.

[54] E. Álvarez, M. A. Cancela and R. Maceiras, "Effect of Temperature on Rheological Properties of Different Jams," International Journal of Food Properties, Vol. 9 No. 1, pp. 135-146, 2006.

[55] K. A. Bunker, J. Go, A. J. Hart, K. N. Hounsell and D. Kim, "Fused Deposition Model Cold Slurry Printer". USA Patent US9883685B2, 2018.

[56] "Robots In Gastronomy Homepage," Robots in Gastronomy, [Online]. Available: https://robotsingastronomy.com/. [Accessed 2501 2020].

[57] E. E. Bischoff White, M. Chellamuthu and J. P. Rothstein, "Extensional rheology of a shear-thickening cornstarch and water suspension," Rheologica Acta, Vol. 49 No. 2, pp. 119-129, 2009.

[58] Z. Liu, M. Zhang, B. Bhandari and C. Yang, "Impact of rheological properties of mashed potatoes on 3D printing," Journal of Food Engineering, 2018.

[59] Z. Quancheng, S. Xinyong, F. Chuanxing, W. Qi, L. Hui, G. Zhiyang and S. Bingqi, "Preparation and process method of compound starch 3D printing material". China Patent CN201710173678, 2017.

[60] E. B. Muliawan, "Rheology and Processing of Mozzarella Cheese," Vancouver, 2008.

[61] Z. Jing, J. Liang, J. Jie, W. Dilong, P. Haijun, W. Jiang, W. Yijiang and F. Xiaokai, "Liquid material 3D printing device that eats". China Patent CN206284362U, 2017.

[62] A. Contractor, C. Kanuga and B. Feltner, "3d-print system with integrated cnc robot and automatic self-cleaning mechanism". USA Patent US15655865, 2016.

[63] Y. Yanghua, “3D prints extrusion-equipment based on food”. China Patent CN205512305U, 2016.

[64] D. E. Fly, "Layered 3D printing with lower viscosity fluid fill”. USA Patent US9440397B1, 2016.

[65] H. Li, S. Liu and L. Lin, "Rheological study on 3D printability of alginate hydrogel and effect of graphene oxide," International Journal of Bioprinting, 2017.

[66] M. Zhang, A. Vora, W. Han, R. J. Wojtecki, H. Maune, A. B. Le, L. E. Thompson, G. M. McClelland, F. Ribet, A. C. Engler and A. Nelson, "Dual-Responsive Hydrogels for Direct-Write 3D Printing," Macromolecules, 2015.

[67] Y. Shao, D. Chaussy, P. Grosseau and D. Beneventi, "Use of Microfibrillated Cellulose/Lignosulfonate Blends as Carbon Precursors: Impact of Hydrogel Rheology on 3D Printing," Industrial and Engineering Chemistry Research, 2015. 
[68] S. Ghosh, X. Wang, J. A. Lewis, S. T. Parker and D. L. Kaplan, "Direct-Write Assembly of Microperiodic Silk Fibroin Scaffolds for Tissue Engineering Applications," Advanced Functional Materials, 2008.

[69] Q. Wang, J. Sun, Q. Yao, C. Ji, J. Liu and Q. Zhu, "3D printing with cellulose materials," Cellulose, Volume 25, Issue 8, pp. 4275-4301.

[70] S. W. Pattinson and A. J. Hart, "Additive Manufacturing of Cellulosic Materials with Robust Mechanics and Antimicrobial Functionality," Advanced Material Technologies, Volume 2, Issue 4, 2017.

[71] S. Xian and S. Yixian, "3D printing forming device and method for cellulose acetate products". China Patent CN201710945610, 2017.

[72] Y. Weimin, C. Baihong, L. Yang, J. Zhiwei, T. Jing and D. Yumei, "Three-dimensional printing forming device and three-dimensional printing forming method for cellulose acetate product". China Patent CN201410554407, 2014.

[73] J. J. Stickel, J. S. Knutsen, M. W. Liberatore, W. Luu, D. W. Bousfield, D. J. Klingenberg, C. T. Scott, T. W. Root, M. R. Ehrhardt and T. O. Monz, "Rheology measurements of a biomassslurry: an interlaboratory study," Rheologica Acta, Vol. 48 No. 9, p. 1005-1015, 2009.

[74] F. A. Kucherov, E. G. Gordeev, A. S. Kashin and V. P. Ananikov, "Three-Dimensional Printing with BiomassDerived PEF for Carbon-Neutral Manufacturing," Angewandte Chemie, Vol. 56 No. 50, pp. 15931-15935, 2017.

[75] C. Jianchen, W. Shijian, Z. Zhaozhong and J. Jinyun, "Biomass wood-plastic composite material for 3D (threedimensional) printing and preparation method for biomass wood-plastic composite material". China Patent CN104356618B, 2016.

[76] Z. Jinmin, Z. Li, L. Zhenhui, W. Yang and Y. Xingchen, "3D printing biomass composite and preparation method thereof'. China Patent CN201610375959, 2016.

[77] W. Zhiguo, X. Junfei, Z. Xiaofan and M. Jinxia, "Preparation method of cellulose based 3D printing wire". China Patent CN201510881126, 2015.

[78] X. Cao, Z. Jiang, W. Cui, Y. Wang and P. Yang, "Rheological Properties of Municipal Sewage Sludge: Dependency on Solid Concentration and Temperature," Procedia Environmental Sciences, Vol. 31, pp. 113-121, 2016.

[79] Y. Cheng and H. Li, "Rheological behavior of sewage sludge with high solid content," Water Science \& Technology, Vol. 71 No. 11, pp. 1686-1693, 2015.

[80] W. Wenlong, L. Guolin, Z. Xiqiang, M. Yanpeng, S. Jing and S. Zhanlong, "System and method for preparing building 3D printing material by using municipal waste and industrial solid waste," p. CN201710160161, 2017.

[81] D. W. Van Krevelen, Proterties of Polymers, 4th completely revised edition, Amsterdam: Elsevier, 2009.

[82] J. E. Mark, Physical Properties of Polymers Handbook, 2nd edition, New York: Springer Science + Business Media LLC, 2007.

[83] S. C. Ligon, R. Liska, J. Stampfl, M. Gurr and R. Mülhaupt, “"'Polymers for 3D Printing and Customized Additive Manufacturing," Chemical Reviews, Vol. 117 No. 15, p. 10212-10290., 2017.

[84] M. Brillinger, C. Pichlkastner, F. Haas, A. Trummer and M. Abdul Hadi, "Additive manufacturing of salt hydrates: Primary process parameters and case study," in review, 2020.

[85] J. Peels, “3D Printed Food: Easy as Pie?,” 0709 2017. [Online]. Available: https://3dprint.com/186844/3dprinted-food-easy-as-pie/. [Accessed 2501 2020].

[86] R. Heymann, "Vorrichtung und Verfahren zur Herstellung von Formkörpern". Germany Patent DE102013216855A1, 2013.

[87] C. D. Fry, J. D. Locondro and G. N. Naware, "Apparatus and method for producing objects utilizing threedimensional printing". USA Patent US20160096327A, 2016.

[88] D. Foresti, D. Poulikakos and M. K. Tiwari, “Acoustophoretic printing apparatus and method". USA Patent US9878536B2, 2018. 